\title{
AVALIAÇÃO DOS MÉTODOS DE EXTRAÇÃO SEQUENCIAL DE TESSIER, KELLER E MILLER NA DETERMINAÇÃO DE FERRO NATIVO EM TRÊS TIPOS DE SOLOS: ORGÂNICO, BRUNIZEM E LATOSSOLO
}

Otavio Raymundo Lã* e Cristina Maria Barra

Departamento de Química, Instituto de Ciências Exatas, Universidade Federal Rural do Rio de Janeiro, Antiga Rodovia Rio-São Paulo, km 47, 23851-970 Seropédica - RJ

Nelson Moura Brasil do Amaral Sobrinho e Nelson Mazur

Departamento de Ciência do Solo, Instituto de Agronomia, Universidade Federal Rural do Rio de Janeiro, Antiga Rodovia RioSão Paulo, km 47, 23851-970 Seropédica - RJ

Ary Carlos Xavier Velloso

Centro de Ciências e Tecnologias Agropecuárias, Universidade Estadual Norte Fluminense, Av. Alberto Lamego, 2000, 28015-620 Campos - RJ

\begin{abstract}
EVALUATION OF TESSIER, KELLER AND MILLER SEQUENTIAL EXTRACTION METHODS IN THE DETERMINATION OF NATIVE IRON IN THREE TYPES OF SOIL: HISTOSOL, OXISOL, AND MOLLISOL. Sequential extraction is not totally effective to dissolve distinct forms of trace elements. The extractive solution, for example, can dissolve less of the target fraction and more than another not wished fraction. The goal of this work is to compare the extraction of native iron with three sequential extraction methods of the heavy metals, using three soils with different physical chemistry characteristics: a histosol, an oxisol, and a mollisol. The results obtained in this work demonstrate that a smaller relation soil/extractor results in a larger extraction in almost all phases. The use of many stages of the sequential extraction, with the purpose of more association of the metal with different components of the soil, can result, among other things, in modification of the substratum by the action of the reagents used, besides reducing the selectivity of the more specific extractors. Readsorption and redistribution of the heavy metals could have happened with larger intensity in the fraction where hidroxilamine was used with higher temperature. Sequential extraction of iron, without enrichment of soil samples, in the respective fractions in each method, it was important to better understand the behavior of the reagents considered specific to each form of the metal in soil.
\end{abstract}

Keywords: sequential extraction; readsorption and redistribution; heavy metals.

\section{INTRODUÇÃO}

Uma das ferramentas para se avaliar o comportamento dos metais traços no solo é a utilização dos chamados métodos de extração seqüencial. Conceitualmente, os metais (ou elementos) contidos em um material sólido podem ser fracionados em formas geoquímicas específicas, e podem ser seletivamente extraídos pelo uso de reagentes apropriados. Cada método apresenta um conjunto de reagentes que deve atacar especificamente a forma geoquímica para o qual foi escolhido ${ }^{1}$.

Na literatura pode-se encontrar muitos trabalhos envolvendo vários métodos de extração seqüencial ${ }^{2,3}$, porém poucos são aqueles em que há um estudo de comparação entre eles ${ }^{4-9}$, o que é decorrente das diferentes condições físico-químicas dos extratores utilizados, as quais acabam afetando diretamente no resultado final da análise das diferentes frações obtidas. A maioria dos trabalhos sobre extração seqüencial em solos e sedimentos utiliza os métodos como se eles fossem por si só absolutos, desconsiderando as diversas interferências que possam existir $^{10}$. Nenhum esquema de fracionamento é totalmente efetivo para dissolver formas geoquímicas distintas dos elementos no material sólido ${ }^{11}$. Uma solução extratora, por exemplo, poderá dissolver menos a fração alvo (elemento ou metal na forma geoquímica específica) e mais de uma outra forma geoquímica não desejada. Esta falta de seletividade dos extratores é um dos principais responsáveis pela baixa eficiência dos métodos ${ }^{12-15}$.

*e-mail: otaviola@ufrrj.br
O primeiro problema ao se criar um esquema de extração para metais traços é selecionar reagentes que sejam efetivos e seletivos em solubilizar uma forma específica do elemento ou metal no solo ${ }^{11}$. Durante as diversas etapas de extração, os metais extraídos por um determinado reagente podem ser adsorvidos em outras fases, seja pela presença de sítios específicos disponíveis, seja pela criação de novos sítios de ligação provocados pela ação dos reagentes utilizados sobre os componentes do solo. Segundo Beckett ${ }^{16}$, este problema não é muito sério nos estágios iniciais dos métodos de extração seqüencial, pois os reagentes utilizados são cátions deslocadores ou complexantes suaves que não alteram substancialmente a amostra. Porém, para os extratores mais fortes, isto provavelmente ocorre, pois um complexante forte pode retirar algum componente da fase sólida, alterando-a, ou um outro reagente pode, ao atacar determinada forma geoquímica, liberar os metais traços oclusos e/ou $\operatorname{adsorvidos}^{17,18}$. Diversos pesquisadores têm questionado a readsorção e a redistribuição de metais pesados ${ }^{2,10,13,17-20}$.

Além dos problemas relacionados à baixa seletividade dos extratores, a readsorção e redistribuição dos elementos, a seqüência de aplicação dos reagentes e a falta de padronização das condições experimentais dificultam ainda mais uma possível comparação entre diferentes trabalhos de pesquisa. Um mesmo procedimento de extração seqüencial aplicado em condições experimentais diferentes pode levar a diferentes distribuições dos metais nas várias frações extraídas $^{14,21-23}$.

O método de Tessier ${ }^{1}$ é o mais citado e utilizado na literatura entre todos os métodos de extração sequiencial. Foi criado para a 
determinação de metais pesados em sedimentos, mas teve o seu uso estendido para solos contaminados ${ }^{2,15,24-34}$. Na seqüência de reagentes utilizados no método de Tessier determinam-se as seguintes frações: a trocável, a ligada a carbonatos, a ligada a oxi-hidróxidos de ferro e manganês, a ligada à matéria orgânica e a residual. Os reagentes da fração carbonato, originalmente utilizados para a solubilização de metais na forma de carbonatos presentes nos sedimentos, em solos oxídicos (intemperizados e ácidos), extraem os metais ligados eletrostaticamente aos componentes do solo e/ou fracamente adsorvidos $^{16}$. A extração dos metais ligados aos oxi-hidróxidos neste método não especifica a qual tipo de óxido estaria o metal ligado e nem o seu grau de cristalinidade.

O método de Keller e Vedy ${ }^{35}$ foi desenvolvido a partir da junção dos métodos de Tessier ${ }^{1}$ e Shuman ${ }^{36}$. A sua principal vantagem é subdividir a fração dos metais associados aos óxidos em dois tipos: os ligados aos óxidos de manganês e os ligados aos óxidos de fer$\mathrm{ro}^{35}$.

O método de Miller ${ }^{11}$, que foi desenvolvido para solos contaminados com metais pesados, apresenta as seguintes frações: solúvel, trocável (com sal neutro), adsorvido especificamente, ácido solúvel, ocluso em óxido de manganês, matéria orgânica, óxido de ferro amorfo, óxido de ferro cristalino e residual. Os reagentes foram selecionados entre aqueles citados na literatura, de acordo com a seletividade para as formas mais ou menos específicas de metais traços do solo ${ }^{11,37}$.

Este trabalho tem como objetivo discutir a especificidade dos reagentes extratores utilizados nos métodos de extração sequiencial de Tessier, Keller e Miller (normalmente utilizados na determinação de metais pesados em solos contaminados e sedimentos), a partir do estudo do comportamento do ferro nativo presente nos óxidos amorfos e cristalinos de três solos de características físico-químicas distintas.

\section{PARTE EXPERIMENTAL}

Três amostras de solo com mineralogias da fração argila diferentes foram selecionadas para este trabalho: latossolo vermelho-amarelo, brunizem avermelhado e orgânico álico. As amostras foram coletadas do horizonte B para o latossolo e o brunizem e, para o solo orgânico, a coleta foi feita à profundidade de $45 \mathrm{~cm}$. Posteriormente, as amostras foram secas ao ar, destorroadas e passadas em peneira de $2 \mathrm{~mm}$ de abertura. A caracterização físico-química do latossolo e brunizem (Tabela 1) foi realizada pelo Serviço Nacional de Levantamento e Conservação do Solo (SNLCS-EMBRAPA) ${ }^{38}$. A caracterização físico-química do solo orgânico (Tabela 1) foi realizada por Conceição ${ }^{39}$. A fração mineral do latossolo é composta, predominantemente, por caulinita, goethita e gibbsita. No brunizem encontrou-se vermiculita aparentemente predominante, caulinita mal cristalizada, mica e vestígios de esmectita. A quantificação dos óxidos de ferro amorfo e cristalino nos solos brunizem e latossolo foi feita utilizando-se o reagente $\mathrm{H}_{2} \mathrm{C}_{2} \mathrm{O}_{4}+\left(\mathrm{NH}_{4}\right)_{2} \mathrm{C}_{2} \mathrm{O}_{4}$, no escuro e sob luz $\mathrm{UV}^{11,40-42}$. No solo orgânico não foram encontrados: areia, silte e argila após a oxidação com $\mathrm{H}_{2} \mathrm{O}_{2}$. Na composição da materia orgânica foram encontrados $10,7 \%$ de ácido fúlvico, 44,2\% de ácido húmico e $45,1 \%$ de humina.

As amostras de solo (em triplicata) foram submetidas às extrações seqüenciais descritas por Tessier ${ }^{1}$, Miller $^{11}$ e Keller $^{35}$ e os reagentes empregados nos respectivos métodos estão descritos na Tabela 2.

Para a digestão total foi utilizada a metodologia descrita em Casartelli e colaboradores ${ }^{43,44}$. A abertura das amostras de solo $(1,0 \mathrm{~g} \pm 0,1 \mathrm{mg})$ foi realizada em reator de Teflon, em sistema fechado, em cinco etapas: na $1^{\mathrm{a}}$ etapa foram adicionados $15 \mathrm{~mL}$ de água régia $\left(3 \mathrm{HCl}: 1 \mathrm{HNO}_{3}\right)$ e $10 \mathrm{~mL}$ de $\mathrm{HF}$, aquecimento em banho
Tabela 1. Caracterização física e química dos solos utilizados no experimento

\begin{tabular}{lccc}
\hline Solo & latossolo $^{38}$ & brunizem $^{38}$ & orgânico $^{39}$ \\
\hline Areia grossa $\left(\mathrm{g} \mathrm{kg}^{-1}\right)^{\mathrm{a}}$ & 240 & 30 & - \\
Areia fina $\left(\mathrm{g} \mathrm{kg}^{-1}\right)^{\mathrm{b}}$ & 100 & 80 & - \\
Silte $\left(\mathrm{g} \mathrm{kg}^{-1}\right)^{\mathrm{c}}$ & 80 & 370 & - \\
Argila $\left(\mathrm{g} \mathrm{kg}^{-1}\right)^{\mathrm{d}}$ & 580 & 520 & - \\
$\mathrm{pH}^{\mathrm{e}}$ & 4,8 & 5,9 & 4,5 \\
${\text { carbono orgânico }\left(\mathrm{g} \mathrm{kg}^{-1}\right)^{\mathrm{f}}}_{\mathrm{SiO}_{2}\left(\mathrm{~g} \mathrm{~kg}^{-1}\right)^{\mathrm{g}}}^{2,3}$ & 3,9 & 126,6 \\
$\mathrm{Al}_{2} \mathrm{O}_{3}\left(\mathrm{~g} \mathrm{~kg}^{-1}\right)^{\mathrm{g}}$ & 214 & 318 & - \\
$\mathrm{Fe}_{2} \mathrm{O}_{3}\left(\mathrm{~g} \mathrm{~kg}^{-1}\right)^{\mathrm{g}}$ & 211 & 186 & - \\
$\mathrm{TiO}_{2}\left(\mathrm{~g} \mathrm{~kg}^{-1}\right)^{\mathrm{g}}$ & 79 & 149 & - \\
$\mathrm{FeO}\left(\right.$ escuro) $\left(\mathrm{g} \mathrm{kg}^{-1}\right)^{\mathrm{h}}$ & 8,7 & 15,8 & \\
$\mathrm{FeO}(\mathrm{ultravioleta})\left(\mathrm{g} \mathrm{kg}^{-1}\right)^{\mathrm{h}}$ & 0,1 & 29,0 & - \\
\hline
\end{tabular}

${ }^{\mathrm{a}}$ separação por tamização com peneira de $200 \mathrm{~mm}$; ${ }^{\mathrm{b}}$ separação por tamização com peneira de $53 \mu \mathrm{m}$; ' diferença entre o total e a soma da $\%$ areia grossa, areia fina e argila; ${ }^{d}$ extração de argila dispersa com $\mathrm{NaOH} 0,1 \mathrm{~mol} \mathrm{~L}^{-1}$, com o uso do método da pipeta; e determinação da atividade hidrogeniônica medida em água; ${ }^{\mathrm{f}}$ oxidação com $\mathrm{K}_{2} \mathrm{Cr}_{2} \mathrm{O}_{7}$ em meio ácido sulfúrico; ${ }^{\mathrm{g}}$ digestão com ácido sulfúrico; ${ }^{\mathrm{h}}$ ferro extraído por oxalato ácido de amônio.

de areia por $12 \mathrm{~h}\left(\mathrm{a} 155^{\circ} \mathrm{C}\right)$. Na $2^{\mathrm{a}}$ e $3^{\mathrm{a}}$ etapas, após a solução remanescente ter sido evaporada à secura foram adicionados $10 \mathrm{~mL}$ da mistura $\mathrm{HF}$ e $\mathrm{HNO}_{3}(1: 1)$ e aquecimento em banho de areia por $3 \mathrm{~h}$ (a $155^{\circ} \mathrm{C}$ ). $\mathrm{Na} 4^{\mathrm{a}}$ e $5^{\mathrm{a}}$ etapas foram adicionados $5 \mathrm{~mL}$ da mistura $\mathrm{HNO}_{3} / \mathrm{HClO}_{4}(1: 1)$ e $\mathrm{HNO}_{3} / \mathrm{H}_{2} \mathrm{O}_{2}(1: 1)$, respectivamente, e aquecimento em banho de areia por $3 \mathrm{~h}\left(\right.$ a $\left.155^{\circ} \mathrm{C}\right)$. Após a quinta etapa de digestão, a solução remanescente foi evaporada quase à secura e o resíduo solubilizado com $\mathrm{HNO}_{3} 1 \mathrm{~mol} \mathrm{~L} \mathrm{~L}^{-1}$ a um volume final de 25,00 mL.

A fração residual foi obtida por diferença entre a digestão total das amostras e o somatório das outras frações de cada método.

A determinação de ferro nos extratos após a extração seqüiencial e digestão total foi feita por espectrofotometria de absorção atômica com chama e os teores de ferro extraído em cada fração de cada método em cada solo são apresentados nas Figuras 1 e 2. Neste trabalho, as diferentes etapas de extração de cada método foram analisadas com base no poder extrator dos reagentes empregados, e foram divididas em fração lábil, solúvel em ácido e especificamente trocável, ligada aos óxidos, ligada à matéria orgânica e residual (Tabela 3).

O teste de Tukey foi utilizado para comparação entre as concentrações médias de ferro entre os solos para um mesmo método, dentro de uma mesma fração e para comparação entre métodos para um mesmo solo, dentro de uma mesma fração (Tabela 4).

\section{RESULTADOS E DISCUSSÃO}

A análise dos resultados foi feita de acordo com a seqüência de adição dos reagentes para cada método, partindo-se daqueles com menor poder de extração (metais dissolvidos na solução do solo, ou ligados eletrostaticamente aos compostos do solo), em direção aos ácidos concentrados usados na digestão das amostras de solo.

\section{Fração do ferro lábil}

A fração denominada de lábil, neste trabalho, é composta pelo somatório das frações aquo-solúvel e sal neutro trocável, que correspondem a T1 (Tessier), K1 + K2 (Keller), e M1 + M2 (Miller), (Tabela 4 e Figura 1) ${ }^{23}$. Tal associação foi feita em razão do método 
Tabela 2. Características de extração dos reagentes utilizados nos diferentes métodos (sem o residual)

\begin{tabular}{|c|c|c|c|c|c|c|c|c|c|}
\hline $\begin{array}{l}\text { Método de } \\
\text { extração }\end{array}$ & $\begin{array}{l}\text { Código } \\
\text { fração }\end{array}$ & Extrator principal & Reagente acompanhante & $\mathrm{pH}$ & $\begin{array}{c}\mathrm{T} \\
\left({ }^{\circ} \mathrm{C}\right)\end{array}$ & $\begin{array}{l}\mathrm{t} \\
(\mathrm{h})\end{array}$ & $\begin{array}{l}\text { Solo: } \\
\text { Extrator }\end{array}$ & Usado para a fração & Obs. \\
\hline \multirow{5}{*}{ TESSIER } & $\mathrm{T} 1$ & $\mathrm{MgCl}_{2} 1 \mathrm{~mol} \mathrm{~L}^{-1}$ & - & 7 & ambiente & 1 & $1: 8$ & Solúvel & \\
\hline & $\mathrm{T} 2$ & $\mathrm{CH}_{3} \mathrm{COOH} 1 \mathrm{~mol} \mathrm{~L}^{-1}+$ & & & & & & & \\
\hline & & $\mathrm{CH}_{3} \mathrm{COONa} 1 \mathrm{~mol} \mathrm{~L}^{-1}$ & - & 5 & ambiente & 5 & $1: 8$ & Trocável + adsorvida & \\
\hline & $\mathrm{T} 3$ & $\mathrm{NH}_{2} \mathrm{OH} . \mathrm{HCl} 0,04 \mathrm{~mol} \mathrm{~L}^{-1}$ & $\begin{array}{l}\mathrm{CH}_{3} \mathrm{COOH} 25 \%(\mathrm{v} / \mathrm{v})+ \\
\mathrm{HNO}_{3} 0,02 \mathrm{~mol} \mathrm{~L}^{-1}\end{array}$ & 2 & 96 & 6 & $1: 20$ & $\begin{array}{l}\text { Óxidos de ferro e } \\
\text { manganês }\end{array}$ & \\
\hline & $\mathrm{T} 4$ & $\mathrm{H}_{2} \mathrm{O}_{2} 30 \%(\mathrm{~m} / \mathrm{v})$ & $\begin{array}{l}\mathrm{HNO}_{3} 20 \%(\mathrm{~m} / \mathrm{v})+ \\
\mathrm{CH}_{3} \mathrm{COONH}_{4} 3,2 \mathrm{~mol} \mathrm{~L}^{-1}\end{array}$ & 2 & 85 & 5 & $1: 16$ & Fração Orgânica & \\
\hline \multirow{5}{*}{ KELLER } & $\mathrm{K} 1$ & $\mathrm{H}_{2} \mathrm{O}$ & - & 7 & ambiente & 1 & $1: 10$ & Solúvel em água & \\
\hline & $\mathrm{K} 2$ & $\mathrm{NaNO}_{3} 0,1 \mathrm{~mol} \mathrm{~L}^{-1}$ & - & 7 & ambiente & 1,25 & $1: 10$ & Trocável em sal neutro & \\
\hline & $\mathrm{K} 3$ & $\mathrm{NH}_{2} \mathrm{OH} \cdot \mathrm{HCl} 0,1 \mathrm{~mol} \mathrm{~L}^{-1}$ & $\mathrm{HNO}_{3} 0,01 \mathrm{~mol} \mathrm{~L}^{-1}$ & 2 & ambiente & 2 & $1: 20$ & Óxido de manganês & \\
\hline & K4 & $\mathrm{NH}_{2} \mathrm{OH} \cdot \mathrm{HCl} 1 \mathrm{~mol} \mathrm{~L}^{-1}$ & $\mathrm{CH}_{3} \mathrm{COOH} 25 \%(\mathrm{v} / \mathrm{v})$ & 2 & ambiente & 4 & $1: 20$ & Óxido de ferro & $*$ \\
\hline & K5 & $\mathrm{H}_{2} \mathrm{O}_{2} 30 \%(\mathrm{~m} / \mathrm{v})$ & $\mathrm{HNO}_{3} 0,02 \mathrm{~mol} \mathrm{~L}^{-1}$ & $<2$ & 85 & \pm 7 & $1: 13$ & Fração orgânica & \\
\hline \multirow{8}{*}{ MILLER } & M1 & $\mathrm{H}_{2} \mathrm{O}$ & - & 7 & ambiente & 16 & $1: 40$ & Solúvel em água & \\
\hline & M2 & $\mathrm{Ca}\left(\mathrm{NO}_{3}\right)_{2} 0,5 \mathrm{~mol} \mathrm{~L}^{-1}$ & - & 7 & ambiente & 16 & $1: 40$ & Trocável em sal neutro & \\
\hline & M3 & $\mathrm{Cu}\left(\mathrm{NO}_{3}\right)_{2} 0,05 \mathrm{~mol} \mathrm{~L}^{-1}$ & $\mathrm{Ca}\left(\mathrm{NO}_{3}\right)_{2} 0,1 \mathrm{~mol} \mathrm{~L}^{-1}$ & $<7$ & ambiente & 16 & $1: 40$ & Trocável específico & \\
\hline & M4 & $\mathrm{CH}_{3} \mathrm{COOH} 0,44 \mathrm{~mol} \mathrm{~L}^{-1}$ & $\mathrm{Ca}\left(\mathrm{NO}_{3}\right)_{2} 0,1 \mathrm{~mol} \mathrm{~L}^{-1}$ & 2,5 & ambiente & 8 & $1: 40$ & Ácido solúvel & \\
\hline & M5 & $\mathrm{NH}_{2} \mathrm{OH} . \mathrm{HCl} 0,01 \mathrm{~mol} \mathrm{~L}^{-1}$ & $\mathrm{HNO}_{3} 0,1 \mathrm{~mol} \mathrm{~L}^{-1}$ & 1 & ambiente & 0,5 & $1: 40$ & Óxido de manganês & \\
\hline & M6 & $\mathrm{K}_{4} \mathrm{P}_{2} \mathrm{O}_{7} 0,1 \mathrm{~mol} \mathrm{~L}^{-1}$ & - & \pm 11 & ambiente & 24 & $1: 40$ & Fração orgânica & \\
\hline & M7 & $\begin{array}{l}\left(\mathrm{NH}_{4}\right)_{2} \mathrm{C}_{2} \mathrm{O}_{4} 0,175 \mathrm{~mol} \mathrm{~L}^{-1} \\
+\mathrm{H}_{2} \mathrm{C}_{2} \mathrm{O}_{4} 0,1 \mathrm{~mol} \mathrm{~L}^{-1}\end{array}$ & - & 3,5 & ambiente & 4 & $1: 40$ & Óxido de ferro amorfo & Escuro \\
\hline & M8 & $\begin{array}{l}\left(\mathrm{NH}_{4}\right)_{2} \mathrm{C}_{2} \mathrm{O}_{4} 0,175 \mathrm{~mol} \mathrm{~L}^{-1} \\
+\mathrm{H}_{2} \mathrm{C}_{2} \mathrm{O}_{4} 0,1 \mathrm{~mol} \mathrm{~L}^{-1}\end{array}$ & - & 3,5 & 85 & 3 & $1: 40$ & $\begin{array}{l}\text { Óxido de ferro } \\
\text { cristalino }\end{array}$ & $\begin{array}{l}\text { Em presença de } \\
\text { luz ultravioleta }\end{array}$ \\
\hline
\end{tabular}

$\mathrm{T}$ - temperatura; $\mathrm{t}$ - tempo; ${ }^{*}$ solos com mais ferro, mais reagente.

de Tessier não apresentar a fração aquo-solúvel. É importante enfatizar que, dependendo da quantidade de matéria orgânica, a fração lábil também inclui os metais na forma de complexos orgânicos solúveis que, embora não estejam disponíveis para as plantas e microorganismos, são extraídos pelo extrator sal neutro trocável ${ }^{23,45,46}$.

Na Tabela 4 pode-se observar pelas concentrações de ferro lábil que a quantidade extraída pelo método de Miller (M1 + M2) foi seis vezes maior que no método de Tessier (T1) que, por sua vez, foi apenas 1,5 vez maior que pelo método de Keller $(\mathrm{K} 1+\mathrm{K} 2)$. Vários fatores, tais como relação solo/extrator, tempo de extração, carga do cátion e ânion e concentração da solução extratora, devem ser analisados em conjunto na tentativa de explicar a diferença na extração da fração lábil pelos três métodos.

A concentração dos reagentes extratores não foi, em princípio, tão importante nesta fração. No método de Tessier, onde o reagente extrator tem a maior concentração, deveria se esperar a maior quantidade extraída de ferro, o que não ocorreu. Por outro lado, o efeito da carga do magnésio e cálcio (íons divalentes), dos métodos de Tessier e Miller, em relação ao sódio (monovalente), do método de Keller, na extração, foi relativamente diminuído pelo ferro ser trivalente e, portanto, estar mais associado eletrostaticamente aos compostos do solo pela maior carga. O efeito do ânion na extração do ferro provavelmente não influenciou, já que os complexos de Fe(III) com cloreto e nitrato são fracos, como pode ser observado na Tabela $5^{47}$.

Os fatores que parecem influenciar mais na extração de ferro são o tempo de extração e a relação solo/extrator quando os três métodos são comparados.

A extração do ferro lábil nos métodos de Keller e Miller (Tabelas 2 e 3) ocorre em presença de água além do extrator sal neutro trocável porém, a maior relação solo:extrator (1:40) e também o maior tempo de extração (16 h), no método de Miller resultam em maior quantidade extraída de ferro (Figura 1). Comparando os métodos de Miller e Tessier, observa-se que estes foram os fatores que influenciaram mais na extração da fração do ferro lábil. Esta associação tempo de extração e relação solo/extrator resultou numa remoção maior no latossolo pelo método de Miller de, aproximadamente, 8,5 vezes em relação ao Keller; já nos solos orgânico e brunizem, cerca de doze e dezessete vezes, respectivamente (Figura 1). Quando a análise é feita relacionando somente os métodos de Keller e Tessier, verifica-se que os fatores que mais influenciaram na extração do ferro lábil foram concentração e carga do cátion extrator, apesar da relação solo:extrator e tempo de extração maiores no método de Keller.

\section{Fração do ferro solúvel em ácido e especificamente trocável}

O termo fração solúvel em ácido e especificamente trocável utilizado neste trabalho inclui os metais eletrostaticamente associados aos solos e/ou fracamente adsorvidos (ligados aos carbonatos) ${ }^{16,48}$, os que podem ser retirados ou por um íon mais específico para o sítio ocupado ${ }^{49,50}$, ou por um ligante mais efetivo ou por $\mathrm{H}^{+}$(baixo valor de $\mathrm{pH})^{51}$. Esta fração corresponde à T2, em Tessier, e ao somatório de M3 e M4, em Miller. Nesta fração do metal solúvel em ácido e especificamente trocável, a discussão não foi feita para o método de Keller, pois nele não se utiliza extrator para esta fração.

Em todos os solos, apesar de os extratores da fração lábil do método de Miller (M1 e M2) terem retirado mais ferro que o extrator T1 do método de Tessier, o extrator $\mathrm{Cu}\left(\mathrm{NO}_{3}\right)_{2}$ (M3) extraiu, ainda assim, bem mais que o tampão acetato (T2) do método de Tessier (Figura 1). Esta maior extração pode ter sido ocasionada pela maior relação solo/extrator no método de Miller, comparado ao de Tessier, $1: 40$ e 1:8, bem como ao tempo de extração de 16 e $5 \mathrm{~h}$, respectivamente (Tabela 2), associado ao fato de o íon $\mathrm{Cu}^{2+}$ conseguir deslocar mais fortemente os metais ligados ao solo ${ }^{52}$. 

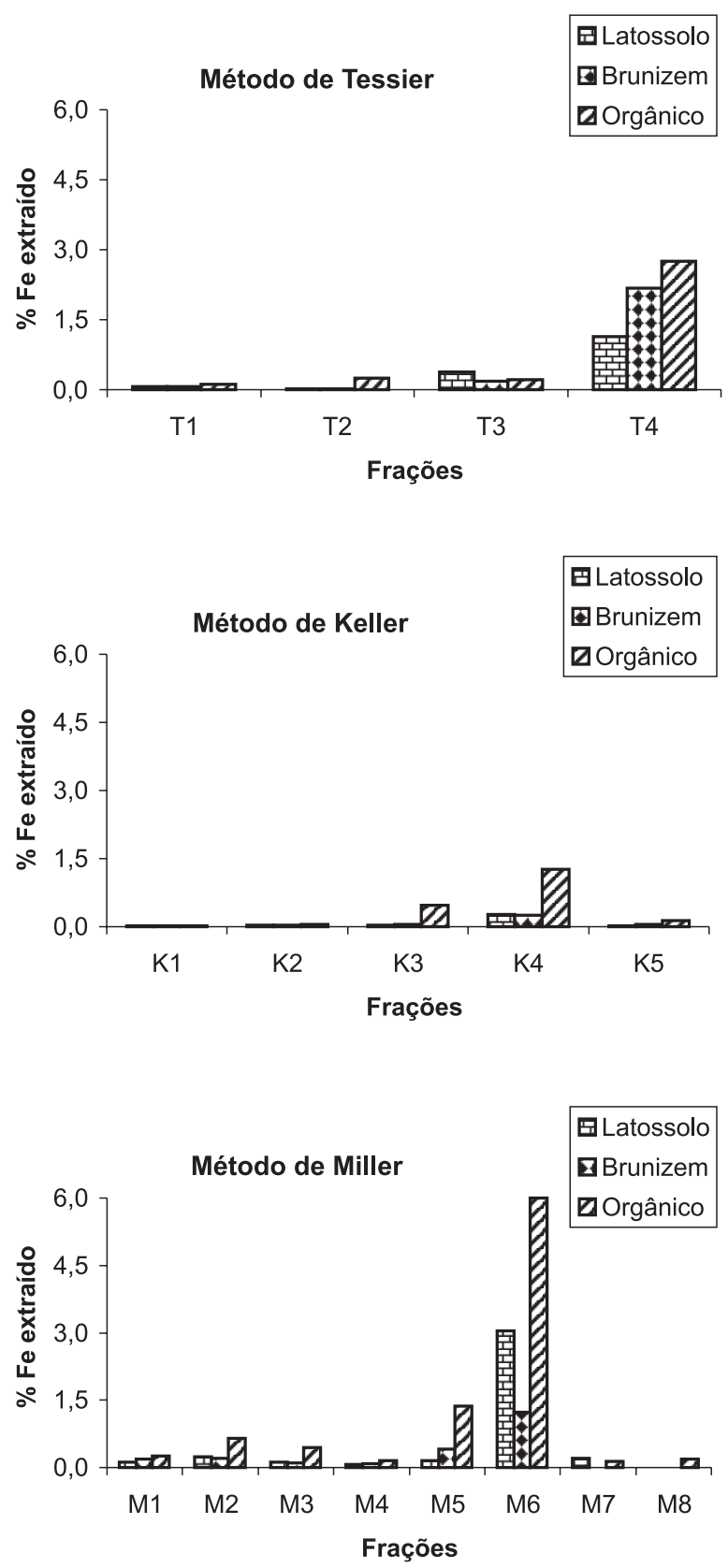

Figura 1. Distribuição percentual de ferro nas diferentes frações obtidas em cada método de extração seqüencial para cada tipo de solo. A fração residual de ferro obtida em todos os métodos não foi incluída; para o brunizem não foram incluídas as frações M7 e M8; para o latossolo não foi incluída a fração M8.
Método de Tessier

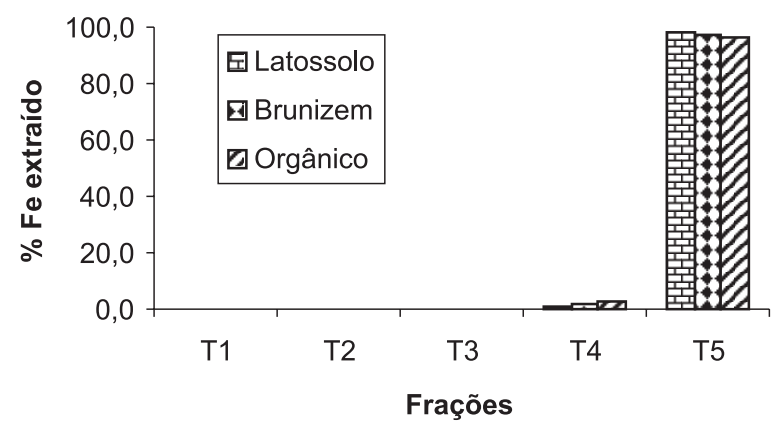

Método de Keller

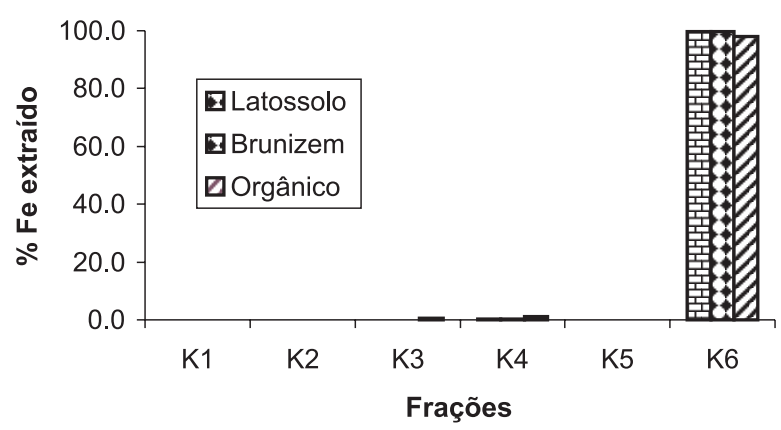

Método de Miller

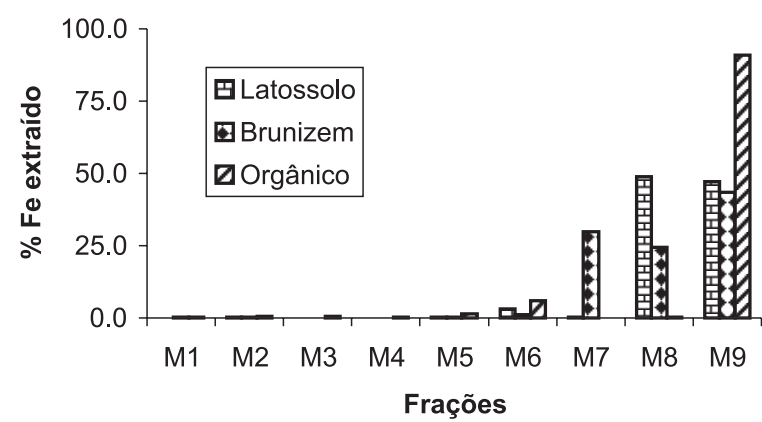

Figura 2. Distribuição percentual de ferro nas diferentes frações obtidas em cada método de extração seqüencial para cada tipo de solo.

Tabela 3. Associação das frações em função do poder de extração dos reagentes utilizados nos três métodos de extração

\begin{tabular}{|c|c|c|c|}
\hline Frações & Tessier & Keller & Miller \\
\hline Lábil & $\mathrm{T} 1$ & $\mathrm{~K} 1+\mathrm{K} 2$ & $\mathrm{M} 1+\mathrm{M} 2$ \\
\hline Solúvel em ácido e/ou trocável especificamente & $\mathrm{T} 2$ & - & $\mathrm{M} 3+\mathrm{M} 4$ \\
\hline Ligada aos óxidos & $\mathrm{T} 3$ & $\mathrm{~K} 3+\mathrm{K} 4$ & $\mathrm{M} 5+\mathrm{M} 7+\mathrm{M} 8$ \\
\hline Ligada à matéria orgânica & $\mathrm{T} 4$ & K5 & M6 \\
\hline Residual & TOTAL- ( Tessier $)$ & TOTAL- ( Keller $)$ & TOTAL- ( Miller $)$ \\
\hline
\end{tabular}

$\sum$ Tessier $=\sum \mathrm{T} 1+\mathrm{T} 2+\mathrm{T} 3+\mathrm{T} 4 ;$ Keller $=\sum \mathrm{K} 1+\mathrm{K} 2+\mathrm{K} 3+\mathrm{K} 4+\mathrm{K} 5 ;$ Miller $=\sum \mathrm{M} 1+\mathrm{M} 2+\mathrm{M} 3+\mathrm{M} 4+\mathrm{M} 5+\mathrm{M} 6+\mathrm{M} 7+\mathrm{M} 8$ 
Tabela 4. Concentração de ferro $\left(\mathrm{mg} \mathrm{kg}^{-1}\right)$ nativo extraído com o uso de reagentes de três métodos de extração seqüencial

\begin{tabular}{|c|c|c|c|c|c|c|}
\hline Solos & $\begin{array}{l}\text { Método } \\
\text { Extração } \\
\text { seqüencial }\end{array}$ & Lábil & $\begin{array}{l}\text { Extração de } \\
\text { Solúvel em ácido } \\
\text { e/ou trocável } \\
\text { especificamente }\end{array}$ & $\begin{array}{l}\text { Ligados aos } \\
\text { óxidos }\end{array}$ & $\begin{array}{l}\text { Ligado à } \\
\text { matéria } \\
\text { orgânica }\end{array}$ & Residual \\
\hline \multirow{3}{*}{ Latossolo } & Tessier & $28,04 \mathrm{ab}$ B & 7,16 b $\quad$ B & 157,04 a B & 465,26 b B & 40163,80 b A \\
\hline & Keller & $21,71 \mathrm{ab} B$ & - & 123,92 a $B$ & 7,80 a $\mathrm{C}$ & 40667,89 b A \\
\hline & Miller & 141,99 b A & 78,08 b A & 20089,83 b A & 1244,85 a $\mathrm{A}$ & 19266,57 b $B$ \\
\hline \multirow{3}{*}{ Brunizem } & Tessier & 40,46 a $B$ & 10,88 b B & 124,61 a B & 1496,95 a $\mathrm{A}$ & 66910,93 a $A$ \\
\hline & Keller & 25,19 a $\mathrm{C}$ & - & 211,85 a B & 31,57 a $\mathrm{C}$ & 68315,22 a $\mathrm{A}$ \\
\hline & Miller & 271,72 a $\mathrm{A}$ & 125,87 a $\mathrm{A}$ & 37499,07 a $\mathrm{A}$ & 847,37 b $B$ & 29839,80 a B \\
\hline \multirow{3}{*}{ Orgânico } & Tessier & $17,83 \quad \mathrm{~b} \quad \mathrm{~B}$ & 36,24 a $B$ & 31,62 a $\mathrm{A}$ & 415,03 b B & 14548,09 c A \\
\hline & Keller & 9,94 b $\quad$ B & - & 261,84 a $A$ & 20,85 a C & 14756,19 c A \\
\hline & Miller & 136,99 b A & 89,52 b A & 256,13 c A & 903,18 b A & $13663,00 \mathrm{c} \mathrm{A}$ \\
\hline \multirow{3}{*}{ Média } & Tessier & 28,78 & 18,10 & 104,43 & 792,42 & 40540,94 \\
\hline & Keller & 18,95 & - & 199,20 & 20,07 & 41246,44 \\
\hline & Miller & 183,57 & 97,82 & 19281,67 & 998,46 & 20923,13 \\
\hline
\end{tabular}

* Comparação das amostras pelo teste de Tukey, ao nível de significância de 5\%. Resultados com letras iguais não diferem significativamente. Letras minúsculas: comparação entre solos para um mesmo método, dentro de uma mesma fração. Letras maiúsculas: comparação entre métodos, para um mesmo solo, dentro de uma mesma fração.

Tabela 5. Constantes globais de formação de complexos com $\mathrm{Fe}^{+3}(\beta)$

\begin{tabular}{cccccccc}
\hline Metal & Constantes & \multicolumn{5}{c}{ Ligantes } \\
\cline { 3 - 7 } & $(\log \beta)$ & $\mathrm{NO}_{3}^{-}$ & $\mathrm{Cl}^{-}$ & $\mathrm{OH}$ & $\mathrm{P}_{2} \mathrm{O}_{7}^{4-}$ & $\mathrm{CH}_{3} \mathrm{COO}^{-}$ & $\mathrm{C}_{2} \mathrm{O}_{4}^{2-}$ \\
\hline \multirow{3}{*}{$\mathrm{Fe}$} & $\log \beta_{1}$ & 1,00 & 1,45 & 11,87 & - & 3,20 & 9,40 \\
& $\log \beta_{2}$ & - & 2,10 & 21,17 & 5,55 & - & 16,20 \\
& $\log \beta_{3}$ & - & 1,10 & 30,67 & - & - & $-20,20$ \\
\hline
\end{tabular}

Fonte: Lurie (1975) ${ }^{4}$

A fração ácido solúvel (M4) extraiu 50, 79 e 35\% em relação ao ferro extraído com $\mathrm{Cu}\left(\mathrm{NO}_{3}\right)_{2}$ para o latossolo, brunizem e orgânico, respectivamente (Figura 1). Este alto percentual para o brunizem pode significar, em princípio, a dissolução de algum óxido de manganês, devido à menor acidez do extrator M4 (Tabela 2) ${ }^{51}$.

\section{Extração do ferro ligado aos óxidos}

A fração denominada de ligada aos óxidos neste trabalho corresponde a T3 (em Tessier), a K3 + K4 (em Keller) e M5 + M7 + M8 (em Miller). Os métodos de Tessier e Keller utilizam a hidroxilamina para extrair os metais ligados aos óxidos de ferro e manganês. Porém, segundo Keller e Vedy ${ }^{35}$, este reagente em concentração $1 \mathrm{~mol} \mathrm{~L}^{-1}$ é considerado altamente específico para atacar os óxidos de ferro. Logo, quando comparado ao método de Tessier, que utiliza este reagente em concentração $0,04 \mathrm{~mol} \mathrm{~L}^{-1}$, o método de Keller utiliza hidroxilamina, com concentração de 2,5 e 25 vezes superior (Tabela 2), principalmente, para subdividir a fração dos metais associados aos óxidos naqueles ligados aos óxidos de manganês e nos ligados aos óxidos de ferro, respectivamente.

Na Tabela 4 observa-se para o latossolo que as quantidades de ferro extraídas pelo reagente T3 foram similares ao somatório dos reagentes $\mathrm{K} 3$ e K4, apesar do maior tempo de extração dos últimos, e da concentração da hidroxilamina do primeiro ser 2,5 e 25 vezes menor que a dos outros, respectivamente, e de se ter adicionado, ainda, uma quantidade maior do reagente $\mathrm{K} 4$, em função da maior quantidade de ferro existente no latossolo (Tabela 2). Isto, provavelmente, se deve à maior temperatura de extração utilizada no método de Tessier $\left(96^{\circ} \mathrm{C}\right)$ do que no método de Keller (Tabela 2). Os dados demonstram que no latossolo, talvez pela maior cristalinidade dos óxidos, a temperatura tenha influenciado mais na extração de ferro. Chao e Zhou ${ }^{53}$ também observaram que a temperatura foi o fator preponderante na eficiência da extração de ferro com hidroxilamina.

No brunizem, a fração associada aos óxidos de ferro do método de Keller não foi estatisticamente diferente daquela do método de Tessier, apesar da menor concentração de hidroxilamina utilizada neste último. O reagente utilizado para a fração associada ao óxido de manganês (K3), $\mathrm{NH}_{2} \mathrm{OH} . \mathrm{HCl} 0,1 \mathrm{~mol} \mathrm{~L}^{-1}$, no método de Keller extraiu menor quantidade de ferro que no método de Tessier $\left(\mathrm{NH}_{2} \mathrm{OH} . \mathrm{HCl} 0,04 \mathrm{~mol} \mathrm{~L}^{-1}\right)$. A concentração da hidroxilamina não foi o fator preponderante na extração de ferro (Figura 1).

Na comparação entre os métodos de Miller e Keller para esta fração, o reagente $\mathrm{M} 5\left(\mathrm{NH}_{2} \mathrm{OH} . \mathrm{HCl} 0,01 \mathrm{~mol} \mathrm{~L}^{-1}\right)$, que tem uma concentração 10 e 100 vezes menor que os reagentes K3 e K4, respectivamente, constata-se que algum outro fator que não a concentração ou a temperatura pode estar influenciando na extração. Podese observar na Figura 1 que M5 extraiu no brunizem, 0,4\% do ferro total contra $0,3 \%$ do somatório de K3 com K4. Provavelmente, isto é devido à ação dos vários extratores anteriores do método de Miller, potencialmente mais fortes (comparado ao dos outros métodos), que 
podem ter modificado a matriz, associada ao menor $\mathrm{pH}$ e à maior relação solo/extrator do reagente M5, em comparação aos outros, facilitando, com isto, maior extração de ferro (Tabela 2).

O poder extrator do oxalato ácido de amônio (no escuro), reagente utilizado para a extração de metais associados aos óxidos amorfos (M7) no método de Miller (Figura 2) foi superior quando comparado aos reagentes dos outros dois métodos (T3 e K4). A modificação do solo por extratores anteriores parece estar mais clara para solos pouco intemperizados, como no brunizem, que têm uma grande quantidade de óxidos amorfos. O reagente utilizado para a extração de metais associados aos óxidos amorfos (M7), no método de Miller, extraiu quantidades maiores de ferro no brunizem do que no latossolo, o que é razoável, pois o brunizem tem maior teor de óxidos amorfos de ferro (Figura 2). No latossolo, onde se tem um maior teor de óxidos cristalinos, o reagente para o óxido amorfo extraiu pouquíssimo ferro, o que demonstra a sua relativa especificidade para o óxido amorfo.

Já o oxalato ácido de amônio (M8), em presença de luz ultravioleta, que segundo Miller e colaboradores ${ }^{4}$ dissolve todas as formas de óxidos de ferro, no presente trabalho foi pouco efetivo, chegando a liberar, somente, aproximadamente $50 \%$ do metal no latossolo (Figura 2). Isto demonstra sua ineficiência, já que praticamente $100 \%$ do ferro, neste tipo de solo, encontra-se na forma de óxidos de ferro.

Para o latossolo (Figura 1), o reagente T3 (ferro ligado aos óxidos) foi tão eficiente na extração de ferro quanto o somatório do extraído pelos reagentes M5 (ferro ligado ao óxido de manganês) e M7 (ferro associado ao óxido de ferro amorfo) e isto, provavelmente, foi devido às etapas anteriores no método de Miller, mais eficientes na extração de ferro que os reagentes utilizados no método de Tessier.

$\mathrm{Na}$ fração óxido, principalmente no latossolo e no brunizem, o método de Keller extraiu mais ferro que o método de Tessier, ou seja, o que não foi extraído nas primeiras frações foi removido nesta.

A extração com hidroxilamina $1 \mathrm{~mol} \mathrm{~L}^{-1}$ que, segundo Keller e Vedy $^{35}$, é altamente específica para a solubilização dos metais associados aos óxidos de ferro, não foi seletiva, já que extraiu ferro que não estava associado ao óxido de ferro e nem à argila silicatada no solo orgânico (Tabela 1). Além disto, este reagente não foi eficiente na extração de ferro da fração óxido, principalmente no brunizem, que tem um grande teor de óxidos amorfos de ferro extraíveis por oxalato ácido de amônio (Figura 1).

A extração com hidroxilamina $0,04 \mathrm{~mol} \mathrm{~L}^{-1}$ (T3) do método de Tessier (temperatura de $96{ }^{\circ} \mathrm{C}$ ) demonstrou ser mais eficiente que o reagente K4 do método de Keller. No método de Tessier, contudo, pode ter ocorrido, com maior intensidade, redistribuição dos metais extraídos e, conseqüente readsorção em frações posteriores, provavelmente pela criação de novos sítios de adsorção, devido à temperatura do reagente.

Verificou-se a falta de especificidade dos extratores da fase óxido em todos os métodos, pois extraíram o ferro do solo orgânico em que não se detectou a presença dos compostos inorgânicos (Figura $1)$.

\section{Extração do ferro ligado à matéria orgânica}

Pode ser verificada pela Tabela 4 que a eficiência na extração de ferro ligado à fração orgânica do solo orgânico e latossolo diminuiu na seguinte ordem: método de Milller, de Tessier e de Keller. Já para o brunizem, o método de Tessier (T4) foi significativamente mais eficiente que o de Miller (M6), seguido do método de Keller (K5).

O comportamento diferente no brunizem pode ser devido à redistribuição de ferro proveniente da etapa anterior do método de
Tessier (T3), onde a maior temperatura da hidroxilamina associada ao elevado teor de óxidos amorfos presentes, provavelmente promoveu a criação de novos sítios de adsorção com conseqüente readsorção em frações posteriores (T4), apesar do maior número de fases extratoras com maior relação solo/extrator e maior tempo de extração do método de Miller (Tabela 2).

Para o latossolo o comportamento foi o esperado, já que além da menor quantidade de matéria orgânica neste solo, há uma predominância de óxidos com maior grau de cristalinidade, portanto, é menor a redistribuição de ferro da fração ligada aos óxidos para a fração ligada à matéria orgânica no método de Tessier.

No solo orgânico o reagente pirofosfato de potássio foi mais eficiente na extração de ferro que o peróxido de hidrogênio nos métodos de Tessier e Keller, podendo ser devido à formação de complexos, maior relação solo/extrator, maior tempo de extração e maior número de fases extratoras anteriores, que podem ter modificado mais a matriz.

Hickey e Kittrich, citado por Beckett ${ }^{16}$ e Harrison e colaboradores $^{54}$, mostraram que o aumento da temperatura do reagente T3 do método de Tessier dissolve mais os óxidos de ferro e manganês presentes no solo. $\mathrm{O}$ reagente $\mathrm{T} 3$ extraiu à temperatura de $96^{\circ} \mathrm{C}$, e ele, provavelmente, atacou parcialmente os óxidos de ferro do brunizem e provocou a readsorção na fração orgânica, como foi observado por Rendell e colaboradores ${ }^{20}$. Como no latossolo deve-se ter algum percentual de óxidos amorfos e também o reagente T3 pode ter solubilizado algum óxido que estivesse numa forma menos cristalina, pode ter acontecido uma pequena readsorção na fração seguinte (matéria orgânica), porém, em menor escala que no solo brunizem, que tem um maior teor de óxidos amorfos e, consequientemente, mais sítios de adsorção.

\section{Fração do ferro residual}

A escolha do método de digestão $0^{43,44}$ para a determinação de ferro total deve-se à incapacidade dos reagentes utilizados nos próprios métodos em mostrar efetivamente o total de ferro no solo, aliada à dificuldade em se comparar o residual com reagentes de diferentes forças extratoras. O procedimento utilizado pelo método de Tessier para a determinação do total, que é mais forte que os dos métodos de Keller e de Miller, mostrou-se mais eficiente apenas para o latossolo. A metodologia utilizada ${ }^{43,44}$ foi eficiente para os solos orgânico e brunizem, embora não conseguindo solubilizar totalmente as amostras (material mais refratário), conseguiu digerir mais que o reagente do método de Tessier.

A fração residual para todos os solos e métodos foi obtida através da diferença entre a digestão total das amostras e o somatório das frações extraídas em cada método de extração seqüencial.

As concentrações de ferro residual (Tabela 4) obtidas nos métodos de Tessier e de Keller para os solos brunizem e latossolo não foram estatisticamente diferentes entre si. No entanto, foi com o método de Miller que se obteve a menor fração residual de ferro (Figura 2). Esta diferença deve-se ao poder extrator do oxalato ácido de amônio, que conseguiu solubilizar mais os óxidos de ferro presentes nos solos. Grande parte de ferro residual dos métodos de Keller e de Tessier foi devida à maior ineficiência dos reagentes anteriores em atacar os óxidos amorfos e cristalinos presentes no solo. No solo orgânico, para os três métodos, não houve diferença significativa para o ferro residual.

\section{Avaliação crítica dos métodos utilizados}

A determinação de ferro nas respectivas frações de cada método de extração seqüencial foi importante para se entender melhor o com- 
portamento dos reagentes, considerados específicos, para determinada forma geoquímica do solo.

Dos métodos analisados, o de Keller parece ser o menos apropriado para mostrar a distribuição dos metais nos solos utilizados. O $\mathrm{NaNO}_{3}$ extraiu a menor quantidade de ferro associada à fração lábil. Nos solos ácidos e intemperizados os óxidos e a matéria orgânica têm uma importância fundamental na retenção dos metais pesados e grande parte destes metais está ligada a estes compostos, de fracamente adsorvidos até quase "estruturalmente" adsorvidos. Neste sentido, uma grande falha deste método é a ausência de um reagente extrator para esta fração. Um outro problema deste método está no reagente citado como sendo específico para a fração do óxido de ferro e que, na verdade, ataca muito pouco os óxidos de ferro, quando comparado com a extração pelo oxalato ácido de amônio do método de Miller.

No método de Tessier a questão da redistribuição e readsorção pode ter ocorrido com maior intensidade na fração em que se utilizou a hidroxilamina $0,04 \mathrm{~mol} \mathrm{~L}^{-1}$, em $\mathrm{CH}_{3} \mathrm{COOH}$ a $96^{\circ} \mathrm{C}$. Porém, Shan e Chen ${ }^{17}$ observaram que a redistribuição e readsorção de ferro aconteciam a partir da primeira extração do método de Tessier. Nas outras frações deste método não se pode concluir sobre a importância da redistribuição e readsorção, principalmente devido às diferentes variáveis, tais como tempo de extração, relação solo/extrator, concentração e seletividade dos reagentes.

No método de Miller a readsorção e redistribuição parece ter menor importância provavelmente devido aos seguintes aspectos: maior relação solo/extrator em relação aos outros métodos; associação de $\mathrm{Ca}\left(\mathrm{NO}_{3}\right)_{2} 0,1 \mathrm{~mol} \mathrm{~L}^{-1}$ aos reagentes $\mathrm{Cu}\left(\mathrm{NO}_{3}\right)_{2} 0,05 \mathrm{~mol} \mathrm{~L}^{-1}$ (M3) e $\mathrm{CH}_{3} \mathrm{COOH} 0,44 \mathrm{~mol} \mathrm{~L}^{-1}$ (M4); a maior concentração de prótons ( $\mathrm{pH}$ 1) na fração M5 aumenta a competição de prótons pelos sítios de adsorção, o que mantém o metal dissolvido na solução extratora ${ }^{55}$; os extratores pirofosfato e oxalato ácido de amônio (M6, M7 e M8) parecem não apresentar o problema da readsorção, devido ao poder complexante destes dois ânions, que competem com os sítios de adsorção pelo mesmo metal. Uma desvantagem do método de Miller é o elevado número de frações extraídas, que acabam reduzindo a seletividade de extratores posteriores potencialmente mais específicos.

Neste trabalho pode-se observar ainda o comportamento diferenciado da hidroxilamina em diferentes valores de $\mathrm{pH}$, concentração e temperatura nos três métodos. O extrator parece dissolver formas com certo grau de cristalinidade de ferro em temperaturas elevadas (método de Tessier), porém, à temperatura ambiente parece atacar uma faixa menor de óxidos amorfos (método de Keller, frações K3 e K4). No método de Miller apesar da concentração mais baixa de hidroxilamina (M5), o $\mathrm{pH}$ mais baixo ( $\mathrm{pH} 1,0)$ que nos outros dois métodos $(\mathrm{pH} 2,0)$ provavelmente favoreceu a maior extração de ferro. O reagente oxalato ácido de amônio, no escuro (M7), pareceu ser mais específico na dissolução dos óxidos amorfos. $\mathrm{O}$ mesmo reagente, em presença de luz ultravioleta (M8), conseguiu solubilizar, embora parcialmente, mais o óxido de ferro cristalino, gerando com isto um ferro da fração residual significativamente menor que nos outros dois métodos.

No solo orgânico, embora não tenha sido detectada a presença de argila silicatada e de óxidos, foi observada a extração de ferro nas frações correspondentes aos metais ligados aos óxidos, em todos os métodos. A explicação pode ser a menor acidez dos reagentes extratores, como a hidroxilamina em T3, K3, K4 e M5 e o poder complexante do oxalato nos reagentes M7 e M8 demonstrando que estes reagentes não estão efetivamente atacando os óxidos e sim, os metais que estão adsorvidos em certo grau aos compostos deste solo, e que, portanto, não são tão específicos para os óxidos.

De maneira geral, todos os reagentes utilizados para a fração óxido e fração orgânica, considerados específicos para cada compo- nente do solo, foram ineficientes em atacar o ferro associado a cada fração. Esses reagentes também não são específicos, já que também atacam outros componentes do solo.

Acidez do solo, tipo e concentração de metal pesado, matéria orgânica e óxidos amorfos e tempo de contato com os componentes do solo são fatores que afetam a distribuição e a estabilidade das ligações entre os metais pesados e os componentes do solo.

Assim, no solo pode-se ter desde os metais fracamente adsorvidos até aqueles estruturalmente ligados aos óxidos de ferro (por substituição isomórfica, por exemplo). Logo, nos três métodos de extração seqüencial o reagente considerado específico poderá solubilizar todo o metal pesado que estiver adsorvido na superfície do óxido de ferro, mas deverá ser ineficiente na extração daquele metal estruturalmente ligado, pela incapacidade de dissolver totalmente o óxido de ferro mais cristalino.

\section{REFERÊNCIAS}

1. Tessier, A.; Campbell, P. G. C.; Bisson, M.; Anal. Chem. 1979, 51, 844.

2. Calvet, R.; Boegeois, S.; Msaky, J. J.; J. Environ. Anal. Chem. 1990, 19, 31.

3. Kennedy, V. H.; Sanchez, A. L.; Oughton, D. H.; Rowland, A. P.; Analyst 1997, 122, 89.

4. Raksasataya, M.; Langdon, A. G.; Kim, N. D.; Anal. Chim. Acta 1996, 332, 1.

5. Sheppard, M. I.;Stephenson, M.; $3^{\text {rd }}$ International Conference on the Biogeochemistry of Trace Elements, Paris, France, 1997.

6. Rauret, G.; Talanta 1998, 46, 449.

7. Zhang, T. H.; Quan, S. X.; Fuliang, L. F.; Commun. Soil Sci. Plant Anal. 1998, 29, 1023.

8. Hall, G. E. M.; Pelchat, P.; Water, Air, Soil Pollut. 1999, 112, 41.

9. Schalscha, E. B.; Escudero, P. S.; Ahumada, I. T.; Agrochimica 1999, 43, 126.

10. Nirel, P. M. V.; Morel, F. M. M.; Water Res. 1990, 24, 1055.

11. Miller, W. P.; Martens, D. C.; Zelazny, L. W.; Soil Sci. Soc. Am. J. 1986, $50,598$.

12. Berti, W. R.; Jacobs, L. W.; J. Environ. Qual. 1996, 25, 1025.

13. Hiner, A. V.; Int. J. Environ. Anal. Chem. 1992, 46, 77.

14. Morabito, R.; Fresenius' J. Anal. Chem. 1995, 351, 378.

15. Nowak, B.; Analyst 1995, 120, 737.

16. Beckett, P. H. T.; Adv. Soil Sci. 1989, 9, 143.

17. Shan, X. Q.; Chen, B.; Anal. Chem. 1993, 65, 802.

18. Tipping, E.; Hetherington, N. B.; Hilton, J.; Thompson, D. W.; Anal. Chem. 1985, 57, 1944.

19. Kheboian, C.; Bauer, C. F.; Anal. Chem. 1987, 59, 1417.

20. Rendell, P. A.; Batley, G. E.; Cameron, A. J.; Environ. Sci. Technol. 1980, $14,314$.

21. Rauret, G.; Rubio, R.; Lopez-Sanchez, J. F.; Int. Environ. Anal. Chem. 1989, 36, 69 .

22. Chao, T. T.; Zhou, L.; Soil Sci. Soc. Am. J. 1983, 47, 225.

23. Lã, O. R.; Dissertação de Mestrado, Universidade Federal Rural do Rio de Janeiro, Brasil, 1998.

24. Xian, X. F., J. Environ. Sci. Health, Part A: Toxic/Hazard. Subst. Environ. Eng. 1987, 22, 527.

25. Sheppard, M. I.; Thibault, D. H.; Soil Sci. Soc. Am. J. 1992, 56, 415.

26. Jordan, C. P.; Nickless, G.; Environ. Technol. Lett. 1989, 10, 743.

27. Arunachalam, J.; Emons, H.; Krasnodebska, B.; Mohl, C., Sci. Total Environ. 1996, 181, 147

28. Boughriet, A.; Cordier, C.; Deram, L.; Ouddane, B.; Chamley, H.; Wartel, M.; Fresenius' J. Anal. Chem. 1995, 352, 341.

29. Chlopecka, A.; Bacon, J. R.; Wilson, M. J.; Kay, J.; J. Environ. Qual. 1996, $25,69$.

30. Li, X.; Cole, B. J.; Ramsey, M. H.; Thornton, I.; Analyst 1995, 120, 1415.

31. Ma, L. Q.; Rao, G. N.; J. Environ. Qual. 1997, 26, 259.

32. Twardowska, I.; Kyziol, J.; Fresenius' J. Anal. Chem. 1996, 354, 580.

33. McGrath, D.; Sci. Total Environ. 1996, 178, 37.

34. Shuman, L. M.; Soil Sci. 1979, 127, 10.

35. Keller, C.; Vedy, J. C.; J. Environ. Qual. 1994, 23, 987.

36. Shuman, L. M.; Soil Sci. 1985, 140, 11.

37. McLaren, R. G., Crawford, D. V.; J. Soil Sci. 1979, 24, 172.

38. SNLCS/EMBRAPA, Rio de Janeiro, 1979.

39. Conceição, M.; Dissertação de Mestrado, Universidade Federal Rural do Rio de Janeiro, Brasil, 1989.

40. Rappaport, B. D.; Martens, D. C.; Simpson, T. W.; Reneau, R. B.; J. Environ. Qual. 1986, 15, 133. 
41. Schwertmann, U.; Nature 1966, 212, 645.

42. Smith, B. F. L.; Mitchell, B. D.; Clay Miner. 1984, 19, 737.

43. Casartelli, E. A.; Dissertação de Mestrado, Pontifícia Universidade Católica do Rio de Janeiro, Brasil, 1992.

44. Miekeley, N.; Casartelli, E. A.; Dotto, R. M.; J. Radioanal. Nucl. Chem. 1994, 182,75

45. Alloway, B. J.; Thornton, I.; Smart, G. A.; Sherlock, J. C.; Quinn, M. J.; Sci. Total Environ. 1988, 75, 41.

46. Ure, A. M.; Quevauviller, P.; Muntau, H.; Griepink, B.; Int. J. Environ. Anal. Chem. 1993, 51, 135.

47. Lurie, J. U.; Handbook of Analytical Chemistry, Mir Publishers: Moscou, 1975.
48. Mazur, N.; Tese de Doutorado, Universidade Federal de Viçosa, Brasil, 1997.

49. Emmerich, W. E.; Lund, L. J.; Page, A. L.; Chang, A. C.; J. Environ. Qual. 1982, 11, 178.

50. Miller, W. P.; Tese de Doutorado, Virginia Polytechnic Institute and State University, USA, 1981. (Diss. Abstr. 81 - 21504).

51. Ma, Y. B: Uren, N. C.; Commun. Soil Sci. Plant Anal. 1995, 26, 3291.

52. Barra, C. M.; Curtius, A. J.; Campos, R. C.; Pérez, D. V.; Commun. Soil Sci. Plant Anal. 2001, 32, 1969.

53. Chao, T. T.; Zhou, L.; Soil Sci. Soc. Am. J. 1983, 47, 225.

54. Harrison, R. M.; Laxe, D. P. H.; Wilson, S. J.; Environ. Sci. Technol. 1981, 15, 1378.

55. McBride, M. B.; Adv. Soil Sci. 1989, 10, 1. 